\title{
Urgensi Diversifikasi Destinasi Wisata Religi Untuk Kesejahteraan: Studi Kasus di Kudus
}

\author{
Moh Rosyid \\ Institut Agama Islam Negeri Kudus \\ Mrosyid72@yahoo.co.id
}

\begin{abstract}
This manuscript was written with the aim of discourse on the importance of new tourist destinations in Kudus so as to provide opportunities for economic players to be creative. Sources of national, regional and citizen economy can rely on tourism, especially typical tourism in an area. Kudus Regency has a variety of famous tourist destinations at national and international levels. However, one thing that must be realized by the Kudus regional government is interfaith religious tourism destinations, botanical gardens, and eco museums. This is a form of a new tourist destination that is used as a source of land for the people's economy and the development of small, medium, and medium-sized businesses that are common to small businesses. The initial step that must be prepared is the readiness of concepts, budgets, legal products, program socialization, and mentality for regional governments, board members, business people, and the Kudus community. It's just that, until now, all of that, the local government of Kudus has not discussed it even though the natural facilities support it so that it needs to be initiated in order to realize the Holy City as a tourist city that has unique destinations to be responded by domestic and foreign tourists. People's welfare is the main goal with a good management of tourist destinations.
\end{abstract}

Keywords: tourism, interfaith destinations, and welfare.

\begin{abstract}
Abstrak
Naskah ini ditulis bertujuan mewacanakan pentingnya destinasi wisata baru di Kudus agar memberi peluang pelaku ekonomi bawah berkreasi. Sumber perekonomian nasional, daerah, dan warga dapat mengandalkan dari dunia pariwisata, terutama wisata khas di sebuah daerah. Kabupaten Kudus memiliki ragam destinasi wisata yang masyhur di tingkat nasional dan internasional. Akan tetapi, satu hal yang harus diwujudkan oleh pemda Kudus adalah destinasi wisata religi lintas agama, kebun raya, dan ekomuseum. Hal itu sebagai bentuk destinasi wisata baru yang dijadikan lahan sumber ekonomi rakyat dan pengembangan usaha kecil, sedang, dan menengah yang lazimnya usaha ini oleh rakyat kecil. Langkah awal yang harus disiapkan adalah kesiapan konsep, anggaran, produk hukum, sosialisasi program, dan mental bagi pemda, anggota dewan, pelaku usaha, dan masyarakat Kudus. Hanya saja, hingga kini, semua itu, pemda Kudus belum mewacanakannya meski fasilitas alam mendukungnya sehingga perlu digagas agar mewujudkan Kota Kudus sebagai kota wisata yang memiliki destinasi khas agar direspon wisatawan domestik dan mancanegara. Kesejahteraan rakyat adalah tujuan utama dengan pengelolaan destinasi wisata yang baik.
\end{abstract}

Kata Kunci: kepariwisataan, destinasi lintas agama, dan kesejahteraan. 


\section{PENDAHULUAN}

Sumbangan sektor pariwisata Indonesia semakin besar, surplus jasa perjalanan di neraca pembayaran Indonesia semakin meningkat. Pada tahun 2016, surplus jasa perjalanan 3,639 miliar dollar AS meningkat menjadi 4,85 miliar dollar AS pada tahun 2017 dan 5,338 miliar dollar AS pada tahun 2018. Surplus terjadi karena penerimaan jasa perjalanan wisatawan mancanegara ke Indonesia lebih besar dari pembayaran jasa perjalanan jasa perjalanan wisatawan domestik ke luar negeri. Berdasarkan data Badan Pusat Statistik (BPS) wisman yang datang ke Indonesia pada 2018 sebanyak 15,81 juta kunjungan, meski target pemerintah 17 juta kunjungan. Upaya untuk memenuhi target tersebut agar perolehan devisa lebih banyak dengan memperpanjang masa tinggal dan memperbesar nilai belanja wisman, dan memenuhi selera untuk belanja. Perlunya belajar dari Pemerintah Kota Cirebon Jawa Barat yang mengalokasikan lebih dari Rp 23 miliar untuk menata pedagang kaki lima (PKL), taman, dan pengelolaan sampah untuk mendukung Kota Cirebon sebagai destinasi wisata. Pemberitaan Harian Kompas, Jumat 15 Februari 2019 alokasi anggaran itu meliputi Rp 17 miliar untuk pengelolaan sampah, Rp 5 miliar untuk penertiban dan penataan PKL, dan Rp 1 miliar untuk penghijauan jalan. Hasil evaluasi Badan Perencanaan Pembangunan, Penelitian, dan Pengembangan daerah Kota Cirebon, keluhan wisatawan di Cirebon adalah perihal sampah dan PKL yang belum tertata. Dalam rencana induk pembangunan kepariwisataan Cirebon 2018-2025, kunjungan wisatawan ditargetkan 2,6 juta per tahun dengan lama tinggal dua hari. Tahun 2018 jumlah wisatawan kurang dari 1,5 juta orang dengan lama kunjungan hanya sehari. Padahal Kabupaten Kuningan, tetangga Cirebon mampu mendatangkan wisatawan lebih dari 4 juta wisatawan.

Hal tersebut sebagai penanda bahwa dunia kepariwisataan mendapat perhatian dari pemerintah daerah karena media menyejahterakan warganya. Kesejahteraan rakyat merupakan tanggung jawab pemerintah, pemerintah daerah, dan warga. Keberadaan Pemda harus memfasilitasi eksisnya jalur perekonomian, terutama menghidupkan ragam sumber perekonomian rakyat dengan kebijakan yang tepat sasaran. Upaya yang harus segera direalisasikan Pemerintah Kabupaten Kudus Jawa Tengah adalah memfasilitasi eksisnya destinasi wisata religi yang cakupannya meliputi destinasi lintas agama sehingga lebih luas peminatnya daripada wisata syariah (berbasis Islam) saja. Tarjet yang diharapkan adalah menjaring wisatawan lintas agama. Hal yang perlu dipahami, selama ini, wisatawan ke Kudus didominasi oleh peziarah makam wali, Sunan Kudus dan Sunan Muria yang kedatangannya sebatas berziarah dalam waktu sebentar (tidak selalu memanfaatkan penginapan) sehingga perlu dipola agar mereka juga 
Urgensi Diversifikasi Destinasi Wisata Religi Untuk Kesejahteraan: Studi Kasus di Kudus

singgah rentang waktu tertentu di Kota Kudus. Upaya ini untuk merespon kebijakan Majelis Ulama Indonesia (MUI) dan Kementerian Pariwisata dan Ekonomi Kreatif (Kemenparekraf) yang merealisasikan gagasan wisata syariah pada Juni 2013.

Area wisata di Kudus telah mendukung eksisnya pariwisata, didukung program desa wisata, hanya saja perlu sentuhan dari pemerintah dalam bentuk sosialisasi kebijakan, kemudahan perizinan, dan pengembangan area destinasi yang tepat program. Eksisnya dunia wisata merupakan bagian dari bentuk pemberdayaan ekonomi rakyat. Satu hal yang harus dipahami bahwa nilai ekonomi industri pariwisata di Indonesia pada 2015 hingga semester I-2018 sekitar Rp 67 triliun, 78,6 persennya disumbangkan oleh sektor hotel dan restoran terutama dari wisatawan domestik. Kementerian Pariwisata sedang mengembangkan 10 destinasi wisata prioritas atau dikenal Bali Baru untuk memajukan industri pariwisata nasional pada 2020-2024. Kesepuluh destinasi wisata tersebut dikenal pariwisata bisnis yakni media pertemuan (meeting), insentif, pameran, dan konvensi (MICE). Kesepuluhnya adalah Danau Toba (Sumut), Tanjung Kelayang (Kepulauan Bangka Belitung), Tanjung Lesung (Banten), Kepulauan Seribu (DKI Jakarta), Candi Borobudur (Jawa Tengah), Bromo-Tengger-Semeru (Jawa Timur), Mandalika (NTB), Labuan Bajo (NTT), Wakatobi (Sulawesi Tenggara), dan Pulau Morotai (Maluku Utara). Diutamakannya pariwisata bisnis karena pengeluaran turis tiga kali lipat dibanding dengan wisatawan biasa. Pariwisata bisnis juga untuk alternatif saat musim kunjungan sepi (low season). Keberhasilan pariwisata bisnis menurut Kepala Bappenas Bambang PS Brodjonegoro ditentukan oleh lokasi akomodasi yang terintegrasi, seperti hotel, gedung (gedung pertemuan), dan akses transportasi (Kompas, Selasa 12 Februari 2019).

Pidato Presiden Jokowi pada gala dinner dalam rangka Ulang Tahun ke-50 Persatuan Hotel RI (PHRI) 2019 memaparkan dua bukti aktual. Pertama, Indonesia masuk deretan 6 besar negara terindah di dunia versi Rough Guides, penerbit ternama di Inggris. Kedua, masuk 10 besar negara yang wajib dikunjungi pada 2019 dengan menempati urutan nomor 7 dan menjadi satu-satunya negara ASEAN yang lolos top 10 versi Lonely Planet. Pariwisata menjadi penghasil devisa terbesar di Indonesia 2018 dengan 17 miliar dollar AS mengalahkan devisa dari CPO (crude, palm, oil) atau minyak, kelapa sawit, gas/minyak bumi. Di Indonesia ada 9 destinasi wisata yang berpotensi dipromosikan sebagai destinasi wisata syariah yakni Sumbar, Riau, Lampung, Banten, Jakarta, Jawa Barat, Jawa Timur, Sulawesi Selatan, dan Nusa Tenggara Barat. Kesembilan wilayah tersebut tak termasuk di Jawa Tengah, apalagi di Kudus meskipun Kudus memiliki potensi dikembangkannya destinasi wisata berbasis syariah. Karakter wisata syariah di antaranya fasilitas hotel menyediakan musala, kamar hotel tersedia kitab suci, dapur halal, tak menjual minuman keras 
dan hotel tersebut menerapkan prinsip syariah. Prospek wisata syariah di Indonesia sangat besar karena penganut muslim sekitar 250 juta jiwa atau 88,1 persen dari jumlah penduduk Indonesia, sedangkan populasi muslim dunia 1,6 miliar jiwa. Uang yang digunakan wisatawan muslim di Indonesia pada 2011 mencapai 126 miliar dolar AS atau 1.227,9 triliun, angka ini lebih besar dari uang yang dikeluarkan oleh wisatawan Cina, AS atau Jerman. Berdasarkan kajian Thomson Reuters dalam State of the Global Islamic Economy (2013) total pengeluaran muslim dunia untuk keperluan makanan halal dan gaya hidup mencapai 1,62 triliun dollar AS pada 2012, diperkirakan 2,47 triliun dolar AS pada 2018. Pew Research Center Forum on Religion and Public Life menyebutkan populasi muslim dunai diperkirakan terus bertambah dari 1,6 miliar atau 23,4 persen dari penduduk dunia sebesar 6,9 miliar pada 2010 menjadi sekitar 2,2 miliar atau 26,4 persen dari total penduduk dunia 8,3 miliar pada 2030. Rata-rata pertumbuhan penduduk muslim 1,5 persen setiap tahun. Data State of Global Islamic Economic Report 2016/2017 nilai belanja muslim secara global tahun 2015 diperkirakan lebih dari 1,9 triliun dollar AS. Kategori belanja terbesar dari makanan dan minuman yang mencapai 1,17 triliun dollar AS, disusul model 243 miliar dollar AS, media dan rekreasi 189 miliar dollar AS, wisata mencapai 151 miliar dollar AS, serta farmasi dan kosmetik mencapai 133 miliar dollar AS. Adapun pendapatan makanan dan minuman bersertifikat halal tahun 2015 mencapai sekitar 415 miliar dollar AS. Pendapatan mode muslimah mencapai 44 miliar dollar AS dan penerimaan wisata muslim 24 miliar dollar. Indonesia menempati urutan ke-19 Top Ten Global Islamic Economy Indicator Score tahun 2015. Peringkat pertama ditempati Malaysia (Kompas, Kamis 29 Desember 2016).

Muramnya industri rokok jenis kretek di Kudus sebagai pemacu agar sumber perekonomian lainnya dioptimalkan di Kudus. Kemuraman itu dapat dilihat makin berkurangnya jam pekerja rokok sistem borongan yang mayoritas dikerjakan oleh perempuan. Hal ini akibat menurunnya produksi yang ditarjet perusahaan rokok imbas menurunnya permintaan pasar dan imbas kompetisi. Potensi bidang kepariwisataan di Kudus yang telah ada merupakan aset yang perlu sentuhan nyata agar kesejahteraan bagi warga Kudus terwujud. Satu hal yang memprihatinkan bahwa Kudus memiliki dua destinasi wisata syariah skala nasional, yakni wisata berbasis ritual keagamaan, tetapi penghargaan destinasi wisata yang dianugerahkan oleh Dinas Pariwisata Provinsi Jawa Tengah tahun 2014 belum diperoleh Kudus. Hal ini sebagai penanda bahwa destinasi wisata di Kudus belum mendapat perhatian yang proporsional oleh pemerintah daerah Kabupaten Kudus. Keprihatinan ini agar tidak berlarut-larut, segera merapatkan barisan antara pemerintah dan pelaku wisata di Kudus. 
Urgensi Diversifikasi Destinasi Wisata Religi Untuk Kesejahteraan: Studi Kasus di Kudus

Untuk memotivasi kualitas area wisata, sebanyak 12 obyek wisata di Jawa Tengah mendapat penghargaan dari Dinas Kebudayaan dan Pariwisata Provinsi Jawa Tengah. Penghargaan setiap tahun sekali, pada 2014 diberikan pada 6 obyek wisata swasta yakni Purbasari Pancuran Mas di Purbalingga, Ekowisata Taman Air Indonesia (Etasia) Tlatar di Boyolali, Pantai Cahaya di Kendal, Taman Djamoe Indonesia di Semarang, Museum Batik Danar Hadi di Surakarta, dan Wana Wisata Pendidikan Kali Paingan di Kabupaten Pekalongan dan 6 obyek wisata yang dikelola pemerintah yakni Dataran Tinggi Dieng di Banjarnegara, Kampung Kopi Banaran Kabupaten Semarang, Pantai Suwuk di Kebumen, Agrowisata Pagilaran di Batang, Pantai Kartini di Jepara, dan Pemandian Air Panas di Guci Kabupaten Tegal. Indikator yang dinilai oleh tim juri dari akademisi, pengamat, praktisi, dan unsur Dinbudpar Jateng yakni aspek manajemen, sarana-prasarana, pemberdayaan masyarakat, penerapan Sapta Pesona dan peningkatan jumlah pengunjung. Kedua belas destinasi wisata yang memperoleh penghargaan tersebut tak satu pun berasal dari Kudus. Di sisi lain, target pendapatan asli daerah (PAD) sektor pariwisata di Kabupaten Kudus hingga pertengahan November 2014 hanya menyetor sekitar 71 persen (Rp 1,2 miliar) dari target PAD 2014 sebesar 1,8 miliar. Menurut Kepala Dinas Kebudayaan dan Pariwisata Kudus karena banjir besar yang menghambat jalur transportasi pada awal tahun 2014 dan pengelolaan distinasi wisata oleh swasta. Income wisata Pemkab Kudus terbesar dari obyek wisata Colo mencapai Rp 800 juta (Suara Muria, Suara Merdeka, 20 November 2014).

Catatan perlu perbaikan mendasar berkaitan dengan Kudus di bidang pariwisata yakni di Kudus belum memiliki destinasi wisata kategori wisata religi lintas agama yang dipadukan pengorganisasiannya dengan destinasi wisata syariah (Islam) untuk peningkatan ekonomi rakyat. Menurut Hamid, ekonomi rakyat Indonesia mengalami keterbatasan modal, keterampilan, dan akses pasar sehingga ancaman yang membahayakan bagi kelangsungan ekonomi rakyat adalah arus barang dan modal dari luar negeri yang merupakan konsekuensi logis dari globalisasi ekonomi (2012:83). Pemerintah Kabupaten Kudus perlu berupaya ekstra dalam mengoptimalkan pasar wisata syariah dan religi, khususnya mendatangkan wisatawan dari negara Islam. Produk wisata syariah untuk dikembangkan yang berorientasi pada wisata religi yang tersedia destinasi wisata lintas agama. Sebagai contoh, mengoptimalkan peran masjid-masjid wali, 3 kelenteng di Kudus, beberapa gereja kuno, dan wihara.

\section{Daya Tarik Destinasi Wisata Khas di Kudus}

Untuk memotret daya tarik calon wisatawan ke Kudus, perlu dipahami tabel berikut. 
Benda Cagar Budaya Tak Bergerak di Kabupaten Kudus

\begin{tabular}{|c|c|c|c|}
\hline No & Situs & Alamat & Bentuk \\
\hline 1. & Masjid Menara Kudus & Desa Kauman & Masjid \\
\hline 2. & Masjid Sunan Muria & Colo, Dawe & Masjid \\
\hline 3. & Gapura Masjid Loram & Loram, Jati & Gapura \\
\hline 4. & Langgar Bubar & Demangan, Kota & Masjid \\
\hline 5. & Masjid Baitul Aziz & Kauman, & Masjid \\
\hline 6. & Hadiwarno & Hadiwarno & Gapura \\
\hline 7. & Gapura Bentar Masjid Al- & Kauman, Besito & Gapura \\
\hline 8. & Idrus & Jepang, Mejobo & Makam \\
\hline 9. & Gapura Padurekso & Kaliputu & Makam \\
\hline 10. & Komplek Makam & Krajan, Jati & Makam \\
\hline 11. & Sedomukti & Kauman, Kota & Makam \\
\hline 12. & Makam Jati Krajan & Colo, Dawe & Makam \\
\hline 13. & Makam Sunan Kudus & Sunggingan, Kota & Makam \\
\hline 14. & Makam Sunan Muria & Demangan, Kota & Makam \\
\hline 15. & Makam Kiai Telingsing & Mlati Kidul, Kota & Masjid \\
\hline 16. & Makam Pangeran Puger & Madureksan, Kota & Masjid \\
\hline 17. & Makam Nyai Melati & Kramat, Kota & Masjid \\
\hline 18. & Masjid Madureksan & Simpang Tujuh & Masjid \\
\hline 19. & Masjid Nganguk Wali & Loram, Jati & Masjid \\
\hline 20. & Masjid Agung Kudus & Kauman, Besito & Masjid \\
\hline 21. & Masjid Loram & Krajan, Jati & Pabrik \\
\hline 22. & Masjid al-Idrus & Jl.Sudirman & Rumah \\
\hline 23. & Gapura dan Masjid Jati & Jl.Sudirman & Gedung \\
\hline 24. & Wetan & J1.S.Muria no.58 & Gedung \\
\hline 25. & Pabrik Gula Rendeng & J1.S.Muria no.58 & Gedung \\
\hline 26. & Rumah Dinas PG Rendeng & J1.S.Muria no.10 & Gedung \\
\hline 27. & Gedung SLTP 5 & Jl.Simpang Tujuh & Gedung \\
\hline 28. & Poliklinik Humanica & Jl. Simpang Tujuh & Gedung \\
\hline 29. & Gedung SMP 1 & Jl.Sudirman & Gedung \\
\hline 30. & Rumah Dinas dan Pendapa & Jl.Sudirman & Gereja \\
\hline 31. & Kantor Disduk dan MUI & Jl.Diponegoro & Rumah \\
\hline 32. & Gedung SMP N 3 & Jl.A.Yani & Rumah \\
\hline 33. & Gedung SMP N 2 & J1.A.Yani no.54 & Rumah \\
\hline 34. & Gereja Kristen Jawa & Jl.A.Yani no.47 & Gedung \\
\hline 35. & Mess Karyawan Pabrik & Jl.A.Yani no. 60 & Rumah \\
\hline 36. & Rokok & Jl.A.Yani no.38 & Gedung \\
\hline 37. & Rumah Tinggal & Jl.A.Yani no.34 & Stasiun \\
\hline 38. & Rumah Tinggal & Jl.Tit Sudono & Gedung \\
\hline 39. & Gedung KNPI & Jl.H.R Asnawi & Rumah \\
\hline 40. & Rumah Tinggal & Jl.H.R Asnawi & Gedung \\
\hline 41. & Gedung PT Djarum & Jl.Rahtawu, Besito & Gedung \\
\hline
\end{tabular}


Urgensi Diversifikasi Destinasi Wisata Religi Untuk Kesejahteraan: Studi Kasus di Kudus

\begin{tabular}{|l|l|l|l|}
\hline 42. & Bekas Stasiun Wergu & Kec.Gebok & Rumah \\
43. & SD Muhammadiyah & Jl. Sunan Kudus & Rumah \\
& Rumah Kapal & Keterangan: Juli & \\
Asrama Polri & 2004 berjumlah 32 & \\
Gedung Balai Benih & rumah & \\
Rumah Tinggal Nitisemito & & \\
\hline
\end{tabular}

Data dari Dinas Kebudayaan dan Pariwisata Kudus. Benda cagar budaya tersebut belum dioptimalkan sebagai destinasi wisata sehingga perlu pemberdayaan.

Destinasi wisata tersebut menghadapi kompetitor yakni lokus wisata religi di Jateng (1) Masjid Saka Tunggal di Cikakak, Banyumas. (2) Makam Syekh Maulana Maghribi, Wonobodro, Batang. (3) Makam K.Abdul Kohar, Desa Ngampel, Blora, (4) Makam Ki Hajar Saloka, Desa Samiran, Selo, Boyolali. (5) Makam Mbah Rubi Klampok, Brebes. (6) Makam K.Junaid, Randusanga, Brebes.(7) Gunung Srandil dan Gunung Selok, Karangbenda, Adipala, Cilacap, (8) Masjid Agung, Demak, (9) Makam Sunan Kalijaga, Kadilangu, Demak, (10) Makam Ki Ageng Selo, Tawangharjo, Grobogan. (11) Makam Ratu Kalinyamat, Mantingan, Jepara. (12) Makam Pangeran Hanggawana, Desa Kalisoka, Dukuhwaru, Slawi, (13) Goa Maria Kerep, Ambarawa, Kab.Semarang, (14) Makam alHaddad, Desa Kraton, Tegal Barat, (15) Astana Giri Bangun, Desa Giri Layu, Matesih, Kabupaten Karanganyar dan Makam Samber Nyawa, (16) Makam Ki Ageng Balak, Sukoharjo, (17) Makam Ki Ageng Pandanaran, Desa Paseban, Bayat, Klaten, (18) Makam Sunan Muria, Kudus, (19) Makam K.Dudo, Dukuh Dudan, Tidar, Magelang, (20) makam Syaridin, Syeh Jangkung, Landoh, Kayen, Pati, (21) Makam Sayid Ahmad, Kompleks TPU Sapuro, Pekalongan Barat, (22) Makam Syekh Syamsuddin, Desa Sugihwaras, Pemalang, (23) Petilasan Ardilawet, Desa Panusupan, Rembang, Purbalingga, (24) Bedug Pendowo Masjid Darul Muttaqin, alun-alun Purworejo, (25) Masjid Agung dan Kompleks Makam Adipati Rembang, (26) Makam Pangeran Samudro di Gunung Kemukus, Desa Pendem, Sumberlawang, Sragen. Dari 26 destinasi wisata di Jawa Tengah, destinasi yang ada di Kudus hanyalah nomor (18) Makam Sunan Muria, Kudus.

Tradisi yang bersumber dari aktivitas beraroma keagamaan menjadi rutinitas budaya bagi masyarakat, khususnya yang berada di garis Pantai Utara Pulau Jawa (Pantura), dalam hal ini ber-setting-kan Kota Kudus, Jawa Tengah. Tradisi tersebut masih di-ugemi oleh komunitas budaya berbalutkan aroma agama (Islam). 


\section{Tradisi Tahunan Dandhangan}

Tradisi dandhangan dilaksanakan menjelang datangnya bulan suci Ramadan yang bermula ketika Sunan Kudus akan menentukan 1 Ramadan dengan menabuh beduk yang menghasilkan bunyi 'ndang'. Hasil bunyi tersebut oleh pengguna bahasa yang diilhami teori anomotopetetik (teori bahasa yang memberikan nama aktivitas bersumber dari hasil bunyi) menjadi tradisi ndandangan hingga kini. Tetapi tradisi ini mengalami pergeseran paradigma yakni dari alur pikir agamis an sich menjadi ekonomi oriented yang 'dikomandani' Pemkab. Kudus. Sebagai bukti, pada tahun 2007, tradisi ndandangan yang semula berada di seputar Masjid Al-Aqsho atau Masjid Menara Kudus, digeser oleh Pemkab Kudus di lapangan sepak bola Wergu Kudus dengan tujuan melestarikan ndandangan (hanya) mempertimbangkan aspek ekonomi (lestarinya transaksi jual-beli) dan menafikan esensi dasar ndandangan itu sendiri. Dalihnya respon negatif masyarakat Kudus yang berada di seputar wilayah menjajakkan dagangan ndandangan (Jawa: mremo) karena perilaku sebagian pedagang yang tidak membersihkan lingkungan dan terkesan kumuh.

Respon atas tindakan Pemkab. Kudus, oleh sebagian unsur masyarakat yang dimotori oleh LSM, DPRD Kudus, dan unsur lainnya, pada tahun 2008 ndandangan dikembalikan semula ke wilayah seputar menara Kudus hingga kini. Area yang digunakan berada di sepanjang jalan Sunan Kudus, seputar Menara Kudus, dan disediakannya fasilitas Mandi, Cuci, dan Kakus (MCK) oleh Dinas Kebudayaan dan Pariwisata Kudus. Pelaksanaan ndandangan dalam pengamatan penulis terdapat pergeseran mendasar, meskipun area yang dijadikan lahan ndandangan di seputar Menara Kudus.

Pertama, animo kedatangan warga ke ndandangan tak bertujuan utama mendengarkan bunyi beduk (ndang-ndang), tetapi terkonsentrasi membeli kebutuhan hidup, di antaranya adanya menu khas Kota Kudus yang tersaji hanya dalam acara ndandangan yakni intip yakni makanan khas Kudus yang terbuat dari beras yang dimasak menjadi kerak dengan rasa keripik yang dibumbui kecap yang melekat. Kedua, imbas dari media sosialisasi penentuan 1 Ramadan melalui media massa, maka masyarakat pun tidak antusias dengan detik-detik 1 Ramadan karena lebih intens dengan informasi melalui televisi dan media lainnya. Ketiga, adanya magnit ndandangan telah luntur oleh tradisi rutin tahunan, sehingga tidak lagi menjadi 'heboh' bahkan terkesan biasa-biasa saja. Hal tersebut diakibatkan tradisi yang serupa dilaksanakan di wilayah kabupaten lainnya, bahkan wilayah lokal Kudus dengan model yang identik yakni adanya pasar dadakan. Selain tradisi dandangan, tradisi yang waktunya bersamaan di daerah sekitar Kudus yakni dugderan, sadranan, dan padusan. Sadranan merupakan kegiatan membersihkan makam leluhur (makam 
Urgensi Diversifikasi Destinasi Wisata Religi Untuk Kesejahteraan: Studi Kasus di Kudus

keluarga atau makam tokoh). Sedangkan padusan adalah kegiatan mandi bersama sebagai simbol penyucian diri memasuki bulan Ramadan. Dugderan merupakan tradisi menyambut bulan Ramadan dengan membunyikan bedug (yang berbunyi 'dug') dan meriam (yang berbunyi 'der') secara bergantian menjelang 1 Ramadan di Kota Semarang, tepatnya di halaman Masjid Kauman Semarang sejak tahun 1960. Pelaksanaan dugderan melaksanakan simbolisasi Wali Kota Semarang berperan sebagai Kanjeng Bupati RM Aryo Purbaningrat berjalan menuju Masjid Agung Kauman Semarang dikawal prajurit.

Lunturnya magnit ndandangan tersebut sebagai imbas dari dinamika global yang difasilitasi oleh kecepatan dan ketepatan media massa dalam memenuhi kebutuhan hidup publik. Dalam hal ini penentuan 1 Ramadan oleh pemerintah c.q Kementerian Agama melalui siaran langsung penentuan 1 Ramadan bahkan prediksi penentuan 1 Ramadan telah terpublikasi secara luas jauh sebelum acara ndandangan dilaksanakan dan prediksinya selalu tepat. Untuk melekatkan kembali makna dan dinamika ndandangan agar eksis sepanjang masa, langkah ideal telah dilakukan oleh stakeholders (Yayasan Masjid Sunan Kudus, Pemkab. Kudus, dan tokoh masyarakat dan agama) adalah (1) kemasan ritual ndandangan 'dibalut' dengan seremoni yang melibatkan Pemkab. Kudus, (2) membuat ritual yang lazimnya dilaksanakan di lingkungan Masjid Al-Aqsho, Menara Kudus, seperti tradisi buka luwur, tradisi serupa dengan kemasan yang berbeda juga diperuntukkan pada acara ndandangan. Hal tersebut dilaksanakan dengan harapan direspon optimal oleh masyarakat karena tradisi (ritual) tersebut bermuatan tuah dalam perspektif masyarakat, khususnya masyarakat awam, (3) makna ndandangan perlu ditanamkan sedini awal kepada peserta didik agar dipahami substansi budayanya. Even Dandangan tahun 2010 dimulai tanggal 1 s.d 10 Agustus 2010, lebih dari 160 pedagang luar Kota Kudus mendaftarkan pada penyelenggara yakni Kepala Bidang Pasar dan PKL, Dinas Perdagangan dan Pengelolaan Pasar Kab. Kudus. Pemilahan kawasan even, kawasan menara digunakan daerah pameran potensi daerah se-wilayah pedesaan Kudus. Sedangkan jl. Sunan Kudus, jl.Kiai Telingsing untuk pedagang pakaian, makanan, minuman, dan kerajinan (Jawa Pos, Radar Kudus, 1 Agustus 2010). Dinas Kebudayaan dan Pariwisata Kudus menyadari bahwa ndandangan memiliki nilai budaya dan filosofi, sehingga diadakan karnaval dengan visualisasi berupa penabuhan beduk pertanda datangnya Ramadan, barisan among-among sesaji, ritual rebo wekasan, tradisi ampyang maulud, dan mremo (bazar) dandangan yakni tampilan berbagai jenis makanan khas Kudus yang bermakna ritual seperti nasi kuning, intip ketan, apem, lentog, dan jenang kudus.

\section{Masjid dan Menara Masjid al-Aqsha Kudus beserta Kawasannya}


Peta Desa Kauman (Menara Kudus) sebelah utara menara adalah wilayah Rt 1, sebelah barat Menara wilayah Rt.2, dan sebelah selatan Menara wilayah Rt 3. Jumlah penduduk Desa Kauman tahun 2018 ada 409 jiwa, 3 RT, 1 RW (sedesa), 1 Masjid, dan tak ada musala. Desa Kauman Kecamatan Kota (tempat Masjid Menara) berbatasan sebelah timur dengan Desa Kerjasan (Masjid al-Abyadh), sebelah selatan dengan Desa Langgardelem, sebelah barat berbatasan dengan Desa Damaran, Desa Kajeksan, Krandon, Sunggingan, Purwosari. Menara Masjid al-Aqsha merupakan bangunan vertikal setinggi 18 meter bentuknya menyerupai Candi Jago dan Candi Menara di Jawa Timur. Disebut Candi Menara (bentuknya seperti menara) yakni candi Hindu yang berada di Desa Candirenggo, Kecamatan Singosari, Kabupaten Malang, Jawa Timur merupakan sisa reruntuhan candi sekitar tahun 1800-an. Ahli purbakala Eropa WF Stutteirheim menyebut candi tersebut Candi Cella karena beberapa bagian bangunan candi terdapat celah. Ada pula yang menyebut Candi Cungkup, Candi Renggo karena berlokasi di Desa Candirenggo. Akhirnya disebut Candi Singosari karena berada di wilayah Kecamatan Singosari. Candi Singosari ditemukan pertama oleh Nicolaus Engelhard, Gubernur Pantai Timur Laut Jawa pada tahun 1803, selanjutnya candi mendapat perhatian Thomas Stamford Raffles. Pada 1934-1937 Departemen Survei Arkeologi dari Hindia Timur Belanda merestorasi Candi Singosari. Struktur Candi Singosari berupa mahakala, penjelmaan Dewa Siwa dan Nandiswara, penjelmaan Lembu Nandi yang menjadi dewa penjaga pintu masuk utama candi. Pada bagian atas pintu masuk ruang utama, ruang utara, ruang timur, dan ruang selatan terdapat hiasan kepala Kala atau Banaspati (Raja Hutan). Candi ini terbagi menjadi swahloka (puncak), bwahloka (badan), bhurloka (kaki), dan batur (bagian terbawah candi). Bagian utama candi merupakan lokasi arca Siwa Bhairawa. Sisi utara candi terdapat arca Durga atau Dewi Uma Parwati, isteri Dewa Siwa. Sisi timur merupakan lokasi arca Dewa Ganesya, putra Dewa Siwa dengan Dewi Durga. Bagian selatan berisi arca Resi Guru atau Siwa Guru atau Resi Agastya. Para sejarawan menafsiri bahwa bentuk candi merupakan respon Sunan Kudus mengadopsi dan mengakulturasi karya budaya pemeluk Hindu. Menara masjid berdasarkan inskripsi Arab Kuno yang terdapat di mihrab masjid Al-Aqso, keberadaan masjid lebih dulu jika dibandingkan dengan menara. Masjid didirikan tahun 956 H/1549 M dan nama masjid tersebut adalah Al-Manar atau Al-Aqso yang direnovasi tahun 1919, 1933, 1976, dan 1978.

Menara Masjid Al-Aqsha terdapat pernik-pernik yang tertempel berupa keramik. Sakai Takashi dan Takimoto Tadashi, arkeolog Jepang menelusuri asal mula keramik pada 28 Agustus 2008 yang dikaitkan dengan agama dan peradaban. Menurutnya, dua di antara sekian banyak keramik di Menara (menempel di atas 'pintu' bagian utara dan bagian 
Urgensi Diversifikasi Destinasi Wisata Religi Untuk Kesejahteraan: Studi Kasus di Kudus

selatan) buatan pabrik keramik di Vietnam abad ke-14 hingga 15, meskipun pabrik kini sudah tiada. Keramik di bagian utara berbentuk segi empat, berwarna dasar putih, di bagian tengah berwarna sedikit kebiruan dengan motif bunga berusia paling tua yakni awal abad ke-14 (sekitar tahun $1450 \mathrm{M}$ ), sedangkan keramik di bagian selatan berbentuk lebih besar, lebih menarik, didominasi warna biru bermotif bunga bercorak vietnam dan bentuknya bercorak Islam. Motif ini bisa ditemukan di Istambul, umurnya lebih muda, menjelang atau awal abad ke-15. Pernik keramik sebagian besar di Masjid Menara umumnya buatan China sekitar tahun 1920-an. Produk keramik China berupa mangkok kuno dan miniatur rumah khas melayu abad 15 ada tiga. Pada saat pedagang China singgah di Pantai Purwodadi, berbatasan dengan Desa Wonosoco pun ditemukan Sutodirono, warga Desa Wonosoco, Kecamatan Undaan, Kabupaten Kudus tahun 2000 di petilasan pertapaan Raden Mas Singgah (Sunan Kalijaga) di Pegunungan Kendeng, desa setempat. Tahun 2009 diserahkan pada Dinas Kebudayaan dan Pariwisata Kudus. Dua mangkok berdiameter $15 \mathrm{~cm}$ dan tinggi $5 \mathrm{~cm}$, yang satunya berdiameter $14 \mathrm{~cm}$ (Jawa Pos, Radar Kudus, 6 April 2009). Di area kompleks Masjid al-Aqsha Kudus terdapat peninggalan sejarah yang bernilai tinggi, seperti tempat wudlu (Padasan), tajug (semacam gazebo), gapura, gapura kembar (di dalam masjid), gapura Padureksan (di serambi masjid), Gapura Samping (di samping masjid), dan Gapura Tajug di sisi samping belakang masjid yakni gapura pintu masuk menuju makam Sunan Kudus yang letaknya sebelah depan pojok kanan Masjid Menara Kudus.

Selain Masjid al-Aqsha, terdapat Masjid Langgardalem, diduga kediaman Sunan Kudus berada di sekitar kawasan Menara. Adapun masjid yang pertama kali dibangun Sunan Kudus (di Kudus) -sebelum membangun Masjid al-Aqsha Menara Kudus- yakni Masjid Madureksan (Padureksan) di Desa Langgardalem, kawasan Menara Kudus. Ada pula Masjid Puspitan di Langgardalem (dekat perempatan Sucen).

\section{Masjid dan Makam Sunan Muria}

Menentukan umur sebuah benda sejarah di antaranya dengan memahami artefak yang ditinggalkan oleh pelaku sejarah. Kaitannya dengan masjid Sunan Muria di Gunung Muria, Desa Colo, Kecamatan Dawe, Kudus dengan ditemukannya artefak akhir tahun 2009. Ketika masjid direnovasi tahun 1970, pada penggalian pondasi (dipugar) ditemukan arang yang banyak dan mirip kayu terbakar. Diperkirakan arang tersebut merupakan sisa-sisa pembakaran Masjid oleh Sunan Muria sendiri karena dipuja oleh kakak iparnya, Sunan Kudus. Oleh Sunan Muria agar tidak terjadi pamer tampilan, masjid dibakarnya. Pemugaran masjid, banyak kayu jati yang dimanfaatkan ulang untuk serambi masjid (pawastren) Sunan Muria. Tahun 2009, pawastren direnovasi lagi dan ditemukannya artefak. Penemuan pada sebuah kayu jati yang pernah digunakan penyangga 
(panuwun) atap masjid yang paling atas. Artefak tertulis TJOEN 4.4.1466 TJEPIRING. Kata tjoen dipahami oleh Pengurus Yayasan Masjid dan Makam Sunan Muria, Mastur merupakan nama etnis China. Angka 4.4 merupakan tanggal dan bulan, 1466 merupakan tahun pembuatan diperkirakan abad ke-15, kata tjepiring merupakan nama daerah di wilayah Kabupaten Kendal penghasil kayu jati (Jawa Pos, 18 Juli 2010).

Peninggalan Sunan Muria berupa mihrab Masjid, di atasnya terdapat prasasti berbentuk kaligrafi Arab yang diyakini masyarakat sebagai istighosah (bacaan suci) yang diamalkan Sunan Muria semasa hidupnya. Selain peninggalan kaligrafi adalah batu lumpak dan gentong. Batu lumpak digunakan untuk alas (tatakan, penahan) saka Masjid berjumlah 10 buah. Keberadaan makam dan Masjid Sunan Muria berdiri di atas lahan seluas $4.375 \mathrm{~m}$. Lahan tersebut berada di Gunung Muria. Bagi peziarah yang ingin berkunjung dapat dengan jalan kaki yang melewati jalan bertangga/undakan sebanyak 700 buah dengan jarak 500 meter dari lahan parkir atau tersedia pengojek sepeda motor.

\section{Meningkatkan Fasilitas Destinasi Wisata yang Telah Ada}

1. Destinasi Wisata Fosil

Obyek wisata situs fosil purba di perbukitan Patiayam, Desa Terban, Kecamatan Jekulo diawali penelitian fosil oleh peneliti Belanda Van Es ditemukan gigi graham bawah dan 7 pecahan tengkorak. Penelitian dilanjutkan oleh geolog dari ITB, Dr. Yahdi Yatim menemukan tulang belulang binatang purba seperti stegodon trigono chepalus (sejenis gajah purba), felis sp (macan), bos bubalus palaeoharabau (kerbau), bos banteng paleosondicus (banteng), crocodilus $s p$ (buaya) yang disimpan di musium situs fosil juga tersedia gardu pandang fosil di Gunung Nangka Pegunungan Slumprit petak 21 C milik Perhutani. Peningkatan yang harus dilakukan Pemkab Kudus meliputi mengoptimalkan muatan museum patiayam yang di dalamnya tersimpan ragam fosil hasil dan kepemilikan lahan/tanah yang digunakan untuk meseum, kini lahan masih milik Pemerintahan Desa Terban, Kecamatan Jekulo, Kudus.

2. Budaya Religi Khas Kudus

Kota Kudus juga terdapat tradisi nonbendawi khas yang masih eksis dijadikan sajian bagi wisatawan yang pelaksanaannya setiap tahun. Sebagaimana Mauludan Jawiyan di Desa Padurenen, Kecamatan Gebog, kelompok Terbang Papat di Masjid Menara Kudus, Masjid Agung Kudus, dan masjid lain, komunitas Arab di kampung Demaan, kampung Samin di Desa Larekrejo, Undaan dan Dukuh Kaliyoso, Karangrowo, Undaan, wisata desa lembah dan gua di Wonosoco, Undaan beserta wayang klitik dan dalangnya. Kitab kuna yang belum dapat dibaca isinya (diduga) berisi praktik pertukangan kayu di 
Urgensi Diversifikasi Destinasi Wisata Religi Untuk Kesejahteraan: Studi Kasus di Kudus

Kudus oleh Mbah Rogomoyo di Dukuh Prokowinong, Desa Kaliwungu. Tradisi arak-arakan Tebok Jenang pada 1 Muharram, Rabu Wekasan (hari Rabu pada akhir di bulan Syafar) dan lainnya. Peningkatan yang harus dilakukan Pemkab Kudus meliputi regenerasi dan kualitas sajian tampilan. Selama ini, budaya religi tersebut hanya disaksikan oleh warga setempat, belum dilirik oleh wisatawan.

3. Peninggalan Bendawi

Obyek wisata berupa situs islamisasi di Kudus yakni Masjid Wali di Desa Jepang, Gapura Masjid at-Taqwa Desa Loram, air tiga rasa di Rejenu/Makam Syekh Syadzali di Desa Japan Kecamatan Dawe di Gunung Muria, Makam Raden Mas Panji Sosrokartono. Ia lahir di Mayong, Jepara 10 April 1877 -kakak kandung R.A Kartini-. Ayah Sosrokartono adalah Wedana Mayong, Raden Mas Adipati Semangun Sosroningrat, dengan ibu Mas Ajeng Ngasirah. Tahun 1897 ia mendapat beasiswa program politik balas budi Belanda terhadap Hindia Belanda (Indonesia) sebagai mahasiswa di Sekolah Teknik Sipil Polytechnische School, Delft, Belanda. Setelah dua tahun, Sosro pindah di Fakultas Bahasa Universitas Leiden, Belanda. Sosro menguasai 17 bahasa asing dan 10 bahasa daerah Nusantara. Sosro menjadi wartawan perang pada surat kabar Amerika The New York Herald, cikal bakal The New York Herald Tribune. Kalangan internasional memberi julukan padanya De Javasche Prins atau Pangeran dari Jawa. Sosro merupakan sarjana perdana dari Tanah Air, makamnya di kompleks makam Sedo Mukti Desa Kaliputu, Kecamatan Kota, Kudus. Prinsip dalam kehidupan bersahaja perspektifnya: Sugih tanpa banda (kaya tanpa harta), ngelmu tanpa aji (berilmu tanpa senjata dan aji-aji), ngluruk tanpa bala (ke manapun sendiri), dan menang tanpa ngasorake (menang tanpa merendahkan lawan). Lamun sira banter aja nglancangi (bila anda memiliki kecepatan jangan menyalip), lamun sira landhep aja natoni (bila memiliki ketajaman jangan melukai), lamun sira mandi aja mateni (bila memiliki kekuatan jangan membunuh). Ajarannya Catur Murti (4 kesatuan) yakni menyatunya pikiran, perasaan, perkataan, dan perbuatan untuk dijalani.

\section{Perlunya Destinasi Baru di Kudus}

\section{Pembangunan Museum Islamisasi di Kudus}

Benda sejarah merupakan cagar budaya dan kekayaan budaya bangsa sebagai wujud pemikiran dan perilaku kehidupan manusia yang penting artinya bagi pemahaman dan pengembangan sejarah, ilmu pengetahuan, dan kebudayaan dalam kehidupan bermasyarakat, berbangsa, dan bernegara. Hal itu perlu dilestarikan dan dikelola 
secara tepat melalui upaya perlindungan, pengembangan, dan pemanfaatan dalam rangka memajukan kebudayaan nasional untuk kemakmuran rakyat. Untuk melestarikan cagar budaya (CB), Pemda bertanggung jawab dalam pengaturan perlindungan, pengembangan, dan pemanfaatan CB. CB berupa benda, bangunan, struktur, situs, dan kawasan perlu dikelola oleh pemerintah dan pemda dengan meningkatkan peran serta masyarakat untuk melindungi, mengembangkan, dan memanfaatkan CB. Dengan adanya perubahan paradigma pelestarian cagar budaya, diperlukan keseimbangan aspek ideologis, akademis, ekologis, dan ekonomis guna meningkatkan kesejahteraan rakyat. Bila museum CB berbasis Islam terwujud, ikon kota santri bagi Kudus tak dimakan ikon baru yakni kota kretek. Keduanya, aspek ekonomi dan budaya penting untuk kehidupan warganya.

Di Kudus telah lama didirikan museum kretek, di dalamnya di antaranya mengoleksi benda dan alat produksi dan jenis produksi kretek masa lalu. Muncul pertanyaan, lantas di mana museum yang mengoleksi peninggalan sejarah islamisasi di Kudus? Sebut saja cekathak (pelana kuda Sunan Muria) kini tersimpan di 'almari' kompleks makam Sunan Muria (Umar Said), keris cintoko/ciptoko peninggalan Sunan Kudus yang disimpan di Tajuk kawasan Masjid al-Aqsha Menara Kudus. Ada pula tombak kembar peninggalan Sunan Kudus (Jakfar Shodiq) yang terpasang di samping kanan-kinin mihrab Masjid al-Aqsha Menara Kudus. Benda bersejarah tersebut tertutup untuk publik, sehingga perlu difasilitasi museum dengan pengelola yang profesional. Peninggalan leluhur yang perlu diuri-uri lainnya seperti sumur resapan era Sunan Kudus di titik bangunan pawestren Masjid Al-Aqsha Menara Kudus.

\section{Ragam Tempat Ibadah dalam Satu Kawasan Destinasi Wisata}

Perlu belajar pada bangsa Prancis tatkala Arc de Triomphe selesai dikerjakan tahun 1806, tak banyak yang mengira monumen berbentuk gerbang itu menjadi ikon Kota Paris, bahkan dunia. Awalnya momen mengenang pahlawan Prancis, terutama zaman Napoleon Bonaparte (kemudian menjadi makam sejumlah prajurit tak dikenal pada Perang Dunia I). Monumen didesain Jean Chalgrin itu dihiasi puluhan patung di empat sisi, letaknya strategis sehingga mudah dijangkau pelancong dunia. Hal yang sama terjadi pada Menara Eiffel dibuka 31 Maret 1889 dibuat memperingati seabad Revolusi Prancis tahu 1789. Banyak negara meniru bentuk menara tetapi tak pernah berhasil, termasuk Menara Tokyo. Eiffel setinggi 330 meter (termasuk antena) didesain arsitek Stephen Sauvestre dan dikerjakan Gustave Eiffel. Karya bersejarah di Perancis lainnya seperti museum peninggalan Napoleon dan Obelisk hadiah dari Mesir seribu 
tahun silam. Ada juga Place Charles de Gaulle, Avenue Hoche, dan Avenue des Champs-Elysees, De Louvre. Bagitu juga China memiliki Tembok China semasa kaisar pertama China, Qin Shi Huang, dibangun 500 tahun SM, panjang tembok $6.259 \mathrm{~km}$ di perbukitan. Begitu pula Kota Terlarang (Forbiddean City) dibangun tahun 14061420 terdiri 980 bangunan, 720 ribu meter di Kota Beijing, bekas Istana Kaisar (era Dinasti Ming dan Dinasti Qing). Bangunan terbuat dari kayu jati setebal 20-60 cm. Spirit terhadap peninggalan yang bersejarah itulah yang perlu kita warisi semangatnya sebagaimana dibangunnya anjungan atau Gerbang Kudus Kota Kretek (GKKK) berada di pintu masuk kota Kudus dari Demak yang dianggap sebagai simbol kebangkitan industri rokok kretek. Bangunan setinggi 12 meter, lebar 21 meter, dengan material besi baja putih (stainless) dibangun selama 7 bulan dengan dana Rp 16 miliar dari Pabrik rokok di Kudus. Bangunan diduga termegah di Indonesia itu berbentuk daun tembakau dihibahkan pada Pemkab Kudus. Dengan dibangunnya jembatan jembatan penghubung wilayah Kabupaten Kudus dengan Demak, GKKK meredup bila dipandang karena panjang jembatan yang dioperasikan sejak angkutan mudik lebaran 2019 mengurangi indahnya pemandangan GKKK.

Kondisi tersebut perlunya diwujudkan destinasi wisata lintas agama yakni area wisata yang di dalamnya terdapat ragam tempat ibadah umat agama-agama, mengapa ? pertama, di Jawa Tengah belum ada. Kedua, di Kudus pun terdapat umat agama Hindu tetapi tidak memiliki pura sehingga wisatawan (warga Kudus) dan warga lain dapat menyaksikan bentuk fisik pura. Ketiga, sesuai dengan visimisi Bupati Kudus, H.M Tamzil dan Wabup Hartopo bahwa Kudus menjadi kota religius yakni kota yang toleran. Toleransi dapat dipacu dengan memahami ajaran agama-agama untuk pengetahuan dan mengenal ragam fisik tempat ibadah sehingga tak menganggapnya asing. Di sisi lain, Kudus sebagai kota kretek telah diteguhkan dengan dimilikinya museum kretek, selain Museum Situs Purbakala Patiayam yang diawali penemuan gigi pra graham bawah dan pecahan tengkorak manusia, tulang belulang binatang purba pada lapisan batu pasir tufoon oleh Dr.Yahdi Yatim dari ITB. Pada 1981 ditemukan dua gading gajah purba berukuran 2,5 m dengan diameter $15 \mathrm{~cm}$. Pada 2013 dibuat master plan hingga rencana pembangunan fisik 2015. Situs dirintis sejak 1979 hingga kini telah terkumpul 5 ribu koleksi dari berbagai ukuran. Usia situs temuan mulai dari 700 ribu tahun hingga 1,5 juta tahun seperti gajah purba, harimau dan binatang laut.

\section{Mewujudkan Kebun Raya di Kudus}

Kota Kudus memiliki kekayaan alam, pranata sosial, dan situs arkeologi budaya dan religi yang bersejarah, seperti beberapa masjid 
peninggalan wali penyebar Islam (yang masyhur Sunan Kudus dan Sunan Muria serta lainnya) beserta makamnya, museum kretek serta situs arkeologi Patiayam yang menyimpan fosil prasejarah, dan area 'pemujaan' (situs religi) bagi penganut kepercayaan di Puncak Songo Likur kompleks hutan Rahtawu. Tetapi kekayaan itu belum dilengkapi dengan wahana yang mengoleksi ragam flora dan fauna. Di sisi lain, Kudus memiliki flora fauna khas yang terhampar di pegunungan Muria. Pemkab Kudus perlu membuat kebun raya (KR) berperan sebagai identitas Kudus dan berfungsi sebagai paru-paru kota/desa dan sumber pengetahuan tentang keanekaragaman hayati bagi masyarakat. Selain itu, kenyataannya banyak lahan tandus yang belum dioptimalkan untuk pemberdayaan ekonomi rakyat dan tak tersentuh kebijakan pemulihan secara cepat, menyeluruh, dan sistematis yang perlu diberdayakan dengan mewujudkan KR untuk mendukung pembangunan ekonomi hijau. Kawasan KR merupakan area konservasi untuk menunjang pembangunan ekonomi dan sosial, menjaga tersedianya area resapan air tanah dan tempat tujuan wisata.

Hal yang harus dipersiapkan mewujudkannya adalah memahami potensi puspa (tumbuhan) dan satwa (hewan) yang dikenang dengan peringatan Hari Cinta Puspa dan Satwa setiap 5 November sejak 1993 setelah diadakan KTT Bumi di Brasil 1992 menghasilkan Konvensi PBB mengenai Keanekaragaman Hayati. Hal ini diratifikasi Pemerintah RI dengan UU Nomor 5 Tahun 1994 tentang Lingkungan Hidup. Indonesia disebut mega biodiversity kedua setelah Brasil karena potensi tumbuhan berbunga 10 persen, 27.500 jenis tumbuhan berbunga atau 10 persen dari jenis tumbuhan berbunga di dunia, 12 persen mamalia, 17 persen unggas, 16 persen reptilia, dan 35 persen ikan. Berdasarkan Red Data Book dari Union for Conservation of Nature jumlah flora dan fauna Indonesia yang punah 128 jenis mamalia, 104 jenis burung, 60 jenis ikan, dan 590 jenis tanaman. Ragam hayati diwujudkan konservasi yakni tindakan berbudaya secara sadar pentingnya melestarikan ciptaan Tuhan dengan perlindungan secara teratur untuk mencegah kerusakan dan kemusnahan sumber daya hayati Indonesia. Pada Peringatan Hari Kebangkitan Teknologi Nasional (Harteknas) pada 2004 Presiden Susilo Bambang Yudhoyono menyerukan pentingnya memperbanyak kawasan konservasi. Hal ini ditindaklanjuti oleh Menteri Riset dan Teknologi dengan Surat Edaran Nomor 77/M/VIII/2004 kepada semua gubernur untuk mengagendakan pembangunan $\mathrm{KR}$ di daerah masing-masing berkoordinasi dengan Lembaga Ilmu Pengetahuan Indonesia (LIPI). Ditargetkan pada tahun 2025 Indonesia memiliki 45 kebun raya, terutama dibangun di lahan kritis, sebagaimana Perpres Nomor 93 Tahun 2011 tentang Kebun Raya (KR). KR merupakan 
kawasan konservasi tumbuhan secara eks situ dengan koleksi tumbuhan terdokumentasi dan ditata berdasarkan pola klasifikasi taksonomi, bioregion, dan tematik. Tujuan KR adalah untuk bidang konservasi, penelitian, pendidikan, wisata, dan jasa lingkungan. KR memiliki luas 100 hektar sehingga mampu mengembalikan kondisi lahan rusak sebanyak 4.500 hektar. Penambahan kebun raya pada 2025 secara nasional diharapkan mengurangi 0,005 persen luas lahan kritis. LIPI sejak 1817 mengumpulkan spesimen flora, fauna, dan mikroba hingga kini berjumlah 3 juta spesimen untuk rujukan penelitian keanekaragaman hayati terutama yang endemik untuk pengembangan riset dasar dan rujukan bagi peminat. LIPI akan membangun $21 \mathrm{KR}$ baru di sejumlah daerah. Diharapkan setiap provinsi terdapat KR yang mengoleksi kekayaan hayati setiap daerah untuk kepentingan pendidikan dan penelitian.

Kudus memiliki 'bahan dasar' mewujudkan KR (1) lahan tandus membentang luas, sebagian milik Perhutani di kawasan situs neolitikum Patiayam Terban, perengan hutan di Desa Wonosoco, situs berupa makam yang dikitari hutan jati usia berabad-abad di kawasan Makam Dewi Nawangsih dan Raden Bagus Rinengku di Dukuh Masin, Desa Kandangmas, Kecamatan Dawe dan situs Puncak Songo Likur di Desa Rahtawu. Situs ini memiliki potensi mengundang wisatawan karena terdapat gua alami, sumber air alami, rindangnya hutan alami, dan fauna khas hutan Kudus. (2) berbagai flora dan fauna khas Kudus dapat diakomodasi perawatannya karena selama ini tak terdata identitas dan pemeliharaannya agar tak punah disergap pemburu dan pembalak liar, (3) kepemilikan area wisata sosialbudaya-religi perlu ditambah area wisata flora fauna, (4) dilengkapi area pameran karya budaya khas Kudus seperti wayang kulit klitik khas Kudus dari Desa Wonososco, Kecamatan Undaan, jenang, batik, bordir, alat dapur, dan tradisi Samin Kudus, dan (5) memperkokoh ekonomi rakyat berbasis wong cilik dengan memasarkan produk lokal agar dikenal nasional. Hal ini didukung potensi warga Kudus memiliki karya home industry khas, seperti ragam anyaman berbahan baku bambu, makanan khas kudus seperti jenang/dodol, lentok/lontong dll. yang dapat dipasarkan di area KR. Kendala yang menghadang, adakah iktikad baik Pemda Kudus mewujudkan kawasan konservasi, menghidupkan ekonomi rakyat, dan penyediaan dana pembangunan KR. Pemkab Kudus perlu bermitra dengan pengusaha di Kudus dalam wujud corporate social responsibility (CSR).

\section{Mewujudkan Kudus Kota Ekomuseum}

Istilah ekomuseum (ecomuseum) dari kata ekologi museum (museum ekologi) diperkenalkan oleh pakar permuseuman Prancis, Hugues de Varine dan Georges Henri Riviere De Varine pada 1960. 
Tujuan ekomuseum adalah mengembangkan seluruh wilayah sebagai museum hidup dengan mewujudkan tiga elemen yang terintegrasi. Pertama, pelestarian terhadap jenis warisan berupa alam, tradisi, budaya, dan industri di wilayah tertentu. Kedua, pengelolaan dan pengoperasian dengan partisipasi warga. Ketiga, memfungsikan koleksi tradisi yang terjaga sebagai museum. Sebagaimana Jepang memiliki Tomiura Town yakni ekomuseum dengan tema pertanian, Shimabara City dengan tema pendidikan kesehatan berbasis tanaman obat, prefektur Nagano dan Karuizawa Kota bertema resort budaya, Asahi Town bertema lingkungan. Munculnya ide ekomuseum karena pusaka (heritage) tak hanya dimaknai benda cagar budaya, tapi lingkungan dan masyarakat pewaris tradisi sejarah dilibatkan. Perlunya memahami, di Dusun Selorejo, Desa Krakitan, Kecamatan Bayat, Kabupaten Sleman, Jawa Tengah diresmikan museum pertanian yang memajang alat pertanian, sampel tanah, dan alat permainan anak-anak berbagai daerah dan mancanegara. Juga sebagai pusat info pertanian agar terlestarinya lingkungan pertanian, dilengkapi perpustakaan yang literaturnya tentang pertanian. Begitu pula Museum Bank Indonesia (BI) dibuka sejak 14 September 2010 semula gedung bekas peninggalan De Javasche Bank menampilkan ruang sejarah BI yang terbentuk tahun 1953, perjalanan alat tukar sejak zaman kerajaan hingga kini yakni uang emas zaman Kerajaan Jenggala di sekitar Jatim abad XII, era Kerajaan Mataram Hindu abad IX-XII, uang kampua atau bida terbuat dari kain tenun putri raja era Kerajaan Buton, uang era Jepang yakni dai nippon teikoku seihu, Oeang Republik Indonesia (ORI), uang gunting Sjafrudi, uang BI 1 Juli 1953, dsb. ada pula Museum Tekstil di Jakarta memiliki koleksi kostum tradisional dari 33 provinsi di Tanah Air meliputi kostum saat kelahiran, keseharian, pernikahan, dan kostum upacara kematian. Terdapat 1.980 potong kostum terdiri 786 koleksi kain batik, 709 kain tenun, 325 campuran, 60 koleksi perlengkapan, serta 100 busana dan kontemporer.

Mewujudkan ragam destinasi wisata baru di Kudus memerlukan kesiapan ragam hal yakni kesadaran pentingnya destinasi sebagai sumber ekonomi rakyat yang difasilitasi Pemda, wakil rakyat, pelaku wisata, dan masyarakat secara padu. Dengan optimalnya destinasi ragam wisata aspek lain ikut terbawa sejahtera, antara lain berkembangnya industri kreatif meliputi periklanan, kerajinan, desain, fashion, video, film dan fotografi, permainan interaktif, musik, seni pertunjukan, televisi dan radio, riset dan pengembangan. Kedua belas item industri kreatif tersebut konteks di Kudus yang perlu dioptimalkan adalah kerajinan dan fashion. Kudus merupakan lumbung dua entitas tersebut yang keberadaannya telah 
lama ada dan masih eksis. Hanya saja perlu sentuhan mode kekinian agar direspon oleh pasar. Satu hal yang perlu dipertimbangkan bahwa industri kretek di Kudus makin menyusut karena kebijakan pemerintah di bidang percukaian dan kesehatan mendesak kretek kian terpuruk. Solusi yang segera diantisipasi adalah optimalisasi sektor wisata, wisata syariah, dan destinasi wisata lintas agama. Setiap program yang dilaksanakan oleh pemerintah dan berimbas terhadap kehidupan rakyat, perlu dievaluasi.

Konteks kepariwisataan, perlu melihat kemegahan Bali di balik kemurungan wong cilik. Pembangunan hotel yang banyak dan megah sebagai bukti industri pariwisata di Bali eksis. Namun, apakah semua keuntungan dari pariwisata dapat dinikmati oleh warga masyarakat Bali kelas bawah? Tidak, mengapa? Karena pemodal kecil telah dilibas oleh investor global yang berdampak terpuruknya sumber ekonomi wong cilik. Hal ini disikapi oleh lembaga nonpemerintah yang bergerak dalam bidang perdagangan berkeadilan (fair trade). Sejak tahun 1993 mereka merangkul para perajin di Bali yang tersisih dan terdepak oleh kehadiran pelaku industri pariwisata yang bermodal besar, 85 persen aset pariwisata di Bali dimiliki investor dari luar Bali (Dewanto, 2011). Dengan demikian, kemegahan, tak selalu menguntungkan wong cilik.

\section{KESIMPULAN}

Untuk mengembangkan sumber perekonomian warga Kudus, Pemda Kudus perlu memfasilitasi eksisnya wisata religi dan destinasi wisata baru. Sumber daya lingkungan di Kudus yang potensial memungkinkannya, hanya saja perlu upaya riil dengan memenuhi kriteria destinasi ragam destinasi wisata, khususnya wisata lintas religi. Dinas Kebudayaan dan Pariwisata untuk segera merapatkan barisan dengan stakeholders wisata dan usaha kecil dan menengah di Kudus dengan sosialisasi, pinjaman modal dengan kemudahan, dan dukungan fasilitas yang diperlukan. Hal utama agar destinasi wisata baru di Kudus direspon positif oleh wisatawan adalah membangun destinasi wisata yang khas yakni destinasi ragam tempat ibadah dalam satu kawasan beserta pernikperniknya. Mewujudkan Kudus sebagai kota religius perlu ditopang dengan upaya tersebut. Melanggengkan sikap toleran dengan memahami ragam tempat ibadah sebagai miniatur perwujudan mewarisi sikap Sunan Kudus yang toleran dengan wujud peninggalannya di antaranya bentuk Menara Masjid al-Aqsha Kudus sebagai benda cagar budaya yang unik di dunia.

\section{Daftar Pustaka}

Dewanto, Herpin. Merangkul Mereka yang Tersisih. Kompas, 18 Mei 2011. 
Moh Rosyid

Halaman ini sengaja di kosongkan 